\title{
MÉTODO PARA APLICAR ENTREVISTAS EM PROFUNDIDADE: AVALIANDO CAUSAS DE BAIXO DESEMPENHO EM UM OPERADOR LOGÍSTICO
}

\section{METHOD TO APPLY IN-DEPTH INTERVIEWS: EVALUATING CAUSES OF LOW PERFORMANCE IN A LOGISTICS OPERATOR}

\author{
Gilberto Tavares dos SANTOS $^{1}$, Vicente Henrique de OLIVEIRA FILHO ${ }^{3}$ Rogério ROYER ${ }^{2}$ \\ Ariane FERREIRA ${ }^{4}$, \\ ${ }^{1}$ Universidade Federal do Rio Grande do Sul - UFRGS - Porto Alegre - Brasil \\ gilberto.tavares@ufrgs.br \\ ${ }^{2}$ Universidade Federal de Pelotas - UFPel - Pelotas - Brasil \\ rogroyer@ufrgs.br \\ ${ }^{3}$ Pontifícia Universidade Católica de São Paulo - PUC - São Paulo - Brasil \\ enriqueoliver2005@yahoo.com.br \\ ${ }^{4}$ Universidade Federal de Pelotas - UFPel - Pelotas - Brasil \\ afprosa61@gmail.com
}

\begin{abstract}
Resumo
Este artigo propõe um método para compreender a ocorrência de situações de natureza qualitativa. $O$ método define três macroetapas com procedimentos para planejar, conduzir e tratar os dados coletados por meio de entrevistas em profundidade. Cada etapa é desdobrada em fases sequenciadas que subsidiam a formação de juízo a respeito de um assunto de interesse. Essa sequência descreve as falas de entrevistados, analisa e as interpreta, procurando captar nas falas obtidas pontos comuns de percepção que sirvam de referência para compreender certa situação $e$ auxiliar a tomada de decisão. Para validar o método, aplica-se um estudo de caso realizado em uma empresa pública (operador logístico), onde, por aproximadamente 19 meses, o desempenho operacional manteve-se aquém do esperado em determinada região do Brasil, sem que se pudesse identificar os reais motivos que levaram a empresa a tal resultado. $O$ estudo de caso permitiu entrevistar um grupo de oito empregados previamente escolhidos e levantar possíveis causas do baixo desempenho operacional sob um olhar sistematizado e objetivo. Como resultado, o método mostra-se exequível e de fácil aplicação para ser utilizado em situações semelhantes. O que reforça a sua aplicação é a possibilidade de conjugar ideias que possam desmistificar os níveis de achismo tão comumentemente verificados em ambientes administrativos que, por muitas vezes, preconceituam ações, processos e pessoas, direcionando a tomada de decisão para caminhos equivocados e não conectados à $(s)$ causa(s) raiz do(s) problema $(s)$.
\end{abstract}

Palavras-chave: método, entrevistas em profundidade, descrição, análise e interpretação de dados. 


\section{Introdução}

Para que uma empresa se mantenha competitiva diante dos seus concorrentes, definir metas de desempenho e formas de acompanhamento de resultados é condição obrigatória. O acompanhamento de metas busca corrigir anomalias verificadas e fortalecer aquelas estratégias consideradas como de sucesso (CHURCHILL e PETER, 2010).

Porém, nem sempre as empresas buscam ou sabem compreender as principais causas que contribuem para resultados insatisfatórios. Por muitas vezes, esse entendimento é intuitivo, fundamentado apenas no suposto bom senso. Entretanto, em mercados com competição acirrada, essa compreensão precisa estar referenciada em base científica e dirigida por informações confiáveis e realistas. Nesse sentido, a realização de pesquisas para detectar as principais causas dos maus resultados de desempenho deve ser um recurso presente para contextualizar e sustentar uma futura decisão que reduza muitos dos riscos a que as empresas estão submetidas em razão do empirismo nas tomadas de decisões (HAGUE e JACKSON, 1997).

A coleta de dados acerca de um problema e a subsequente avaliação das suas causas pode ocorrer por meio da realização de pesquisas quantitativas e qualitativas. As pesquisas quantitativas são instrumentos utilizados para testar objetivamente as relações entre variáveis levantadas numericamente. As pesquisas qualitativas buscam captar profundo conhecimento sobre uma situação particular, produzindo riqueza de dados que permita ver um fenômeno na sua totalidade e facilite a exploração de contradições e paradoxos a seu respeito (CASTRO, 2006; CRESWELL, 2010; GREENHALGH e TAYLOR, 1997; VIEIRA e ZOUAIN, 2006).

Uma das técnicas mais importantes de pesquisa qualitativa é a entrevista em profundidade. Esse tipo de entrevista é realizado por meio de perguntas abertas em que um respondente é motivado por um entrevistador a manifestar motivações, crenças, atitudes e sensações subjacentes sobre um determinado tópico (AAKER et al., 2003; JOLLEY e MITCHELL, 2009; MATTAR, 2005). A entrevista procura saber como e por que algo ocorre, em lugar de determinar a frequência de certas ocorrências (GIL, 2010; RICHARDSON, 2007).

As principais vantagens de realizar entrevistas em profundidade incluem: (i) o favorecimento da livre expressão das posições individuais, (ii) a obtenção de maior taxa de respostas, pois os entrevistadores podem realizar acompanhamento mais próximo junto ao entrevistado, (iii) o alcance com mais facilidade a entrevistados com nível mais baixo de instrução, (iv) os esclarecimentos imediatos às dúvidas levantadas pelos entrevistados, e (v) a obtenção de 
maior quantidade de dados por pessoa, se comparada à realização de outro instrumento de coleta de dados (JOLLEY e MITCHELL, 2009; ROESCH, 2005; SAURIN e RIBEIRO, 2000).

O objetivo deste artigo é apresentar um método para utilização de entrevistas em profundidade, com investigação de tópico de origem qualitativa, qual seja, levantar as causas de baixo desempenho em uma empresa que presta serviços como operador logístico. O método surge da necessidade de buscar subsídios para a formação de juízo a respeito de determinada situação, sistematizar a coleta obtida e propiciar subsequente análise e interpretação da situação como um todo.

O método proposto é composto por três etapas que definem procedimentos para planejar, conduzir e tratar dados coletados em entrevistas em profundidade. A lógica do método coleta e descreve as falas de entrevistados, analisa e as interpreta, buscando captar nessas falas pontos comuns de pensamento que sirvam de referência para compreender certa situação e auxiliar a tomada de decisão.

Na prática, o método mostra-se exequível e de fácil sistematização para ser utilizado em situações semelhantes. O que reforça a sua aplicação é a possibilidade de conjugar ideias que possam desmistificar os níveis de achismo tão comumentemente verificados em ambientes administrativos e que, por muitas vezes, preconceituam ações, processos e pessoas, direcionando a tomada de decisão para caminhos equivocados e não vinculados à(s) causa(s) raiz do(s) problema(s).

Para validar a aplicação do método proposto, é apresentado um estudo de caso realizado em uma empresa pública (operador logístico), onde, por aproximadamente um ano, o desempenho operacional manteve-se aquém do esperado em determinada região, sem que se pudesse investigar os reais motivos que levaram a empresa a tal resultado.

O estudo de caso permitiu entrevistar um grupo de oito empregados previamente escolhidos e levantar possíveis causas do baixo desempenho operacional sob um olhar sistematizado e objetivo.

O presente trabalho está apresentado em quatro seções. A primeira seção refere-se à introdução, agora apresentada. A seção 2 aborda o método proposto. A seção 3 refere-se ao estudo de caso para validar o método proposto. A seção 4 apresenta as conclusões relativas aos resultados constatados ao final da pesquisa.

\section{Método Proposto}


O método proposto é composto por três etapas apresentadas na Figura 1.

Figura 1 - Etapas do método para realização de entrevistas em profundidade

\section{Etapa 1 - Planejamento das Entrevistas}

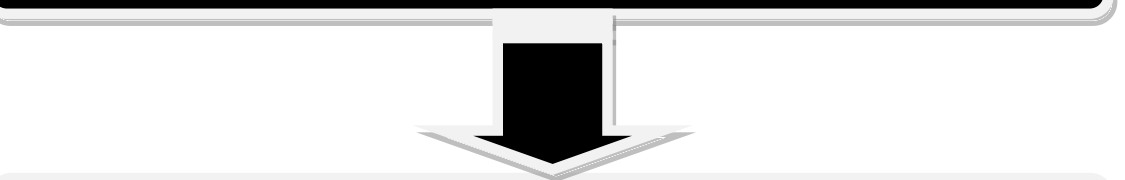

\section{Etapa 2 - Condução das Entrevistas}

\section{Etapa 3 - Tratamento dos Dados Coletados}

Fonte: realizado pelos autores.

\subsection{Planejamento das entrevistas}

O planejamento das entrevistas está estruturado em seis fases sequenciadas (Figura 2) e detalhadas a seguir: (1) definir o propósito da entrevista, (2) identificar e convidar os entrevistados, (3) estabelecer uma oportunidade, (4) elaborar questões e roteiro, (5) detalhar aspectos logísticos, e (6) escolher o entrevistador.

Figura 2 - Fases que compõem a etapa de planejamento das entrevistas

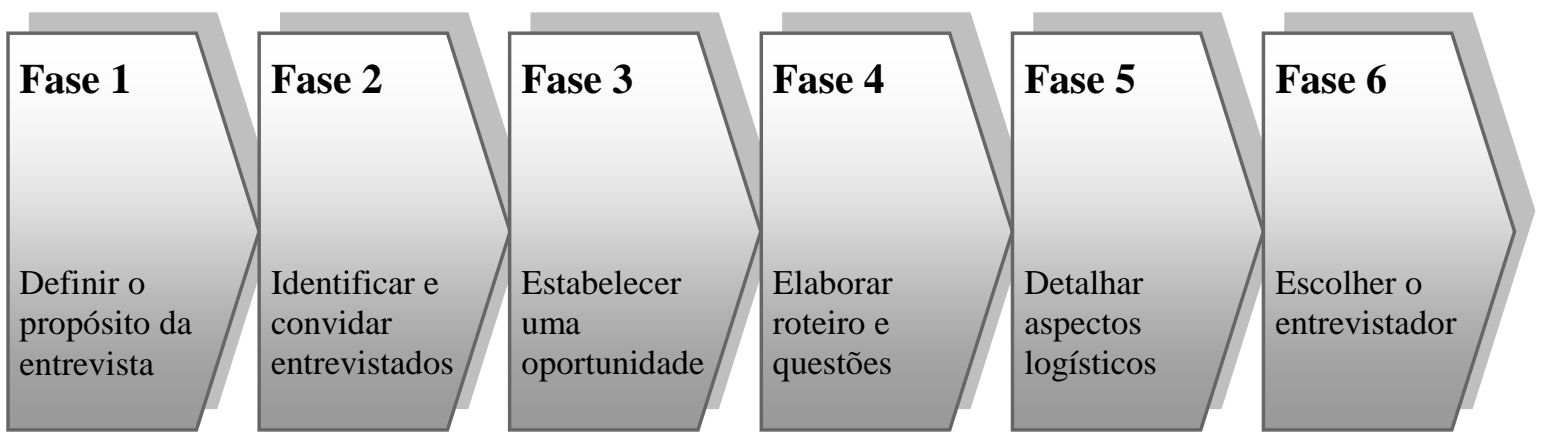

Fonte: realizado pelos autores.

\section{Fase 1 - Definir o propósito da entrevista}

O propósito deve partir de uma real necessidade de informação, em que indagações e dúvidas sejam respondidas. Essa necessidade deve ser explicitada na forma de afirmações, em terminologia tão precisa quanto possível, e escritas de forma concisa (CASTRO, 2006; 
CHURCHILL, 2001).

A definição do propósito pode ser subsidiada pela consulta à documentação existente (documentos internos, relatórios, estudos ou avaliações informais, etc) e às teorias estabelecidas e relacionadas ao tema em debate (CERVO et al., 2007; SANTOS e FOGLIATTO, 2002).

Ao final desta fase tem-se uma ideia mais concreta de como a entrevista será realizada.

\section{Fase 2 - Identificar e convidar entrevistados}

A identificação dos entrevistados depende do propósito da pesquisa. A escolha do número de participantes não deve seguir nenhum esquema amostral probabilístico, haja vista que o objetivo de uma entrevista em profundidade está fortemente vinculado à busca de informações detalhadas e não à sua representatividade estatística. A busca por entrevistados deve seguir uma lógica de interesse direto do entrevistador e relacionada à capacidade das possíveis respostas contribuírem para que o objetivo da pesquisa seja alcançado. Entretanto, nada impede que a escolha dos entrevistados se dê em razão de estratos a serem caracterizados pelo entrevistador diante do conjunto de possíveis entrevistados (CHURCHILL, 2001; RICHARDSON, 2007; SANTOS e FOGLIATTO, 2002).

O número de entrevistas a serem realizadas depende da natureza do problema e do número de novas ideias geradas por entrevista. A quantidade de entrevistas estará concluída tão logo o entrevistador perceba que as ideias obtidas se repetem no decorrer do tempo. Por isso, o número inicial de entrevistados pode ser alterado no decorrer da realização da entrevista, para mais ou para menos (RICHARDSON, 2007).

\section{Fase 3 - Estabelecer uma oportunidade}

O agendamento das entrevistas não tem prazo definido para ocorrer; porém, recomenda-se que os contatos com os entrevistados sejam iniciados, no mínimo, duas semanas antes do evento. Tal prazo permite explicar o propósito da entrevista, marcar datas e horários, assim como realizar qualquer alteração prévia de cronograma (MINAYO et al., 2002).

\section{Fase 4 - Elaborar roteiro e questões}

Organiza-se um conjunto de perguntas que venha a ser aplicado durante as entrevistas e que esteja vinculado ao alcance do propósito definido na fase 1. Um roteiro é recomendável, pois garante a apresentação ordenada das questões aos entrevistados, serve como referência para o entrevistador conduzir cada entrevista de forma similar, assegura o cumprimento do tempo previsto e permite o acréscimo de lembretes específicos relativos a determinadas perguntas (DIEHL e 
TATIM, 2004; RICHARDSON, 2007).

O roteiro deve estar estruturado em três partes: (i) abertura, na qual são inseridas informações relativas aos agradecimentos ao entrevistado, ao propósito e contexto da entrevista, (ii) apresentação das perguntas, e (iii) encerramento, em que se faz menção à colaboração do entrevistado, ao manuseio dos dados coletados na entrevista e aos resultados a serem obtidos e divulgados (RICHARDSON, 2007).

As questões devem ser bem focadas, espontâneas, abertas e ordenadas, partindo de um assunto geral para um assunto específico (AYLOTT e MITCHELL, 1998). Na elaboração das perguntas, convém considerar os seguintes aspectos: $(i)$ se as perguntas devem ser diretas ou indiretas, dependendo da abordagem e da necessidade de informação, (ii) qual a relação e grau de importância da pergunta com o propósito definido, (iii) se os entrevistados possuem conhecimentos suficientes para responder às questões, (iv) se as perguntas sugerem respostas e se isso é conveniente para a entrevista, $(v)$ se as perguntas podem provocar resistências, antagonismos, ressentimentos, (vi) se as palavras empregadas apresentam significação clara e precisa, (vii) se as perguntas não direcionam respostas, e (viii) se as perguntas estão ordenadas de maneira tal que os entrevistados não sejam obrigados a grandes esforços mentais (GIL, 2010; RICHARDSON, 2007; VIEIRA e ZOUAIN, 2006).

Opcionalmente, pode-se aplicar um pré-questionário a entrevistados potenciais. O préquestionário possibilita ratificar a inclusão de participantes e testar perguntas a serem incluídas, alteradas ou retiradas da entrevista (ROESCH, 2005).

\section{Fase 5 - Detalhar aspectos logísticos}

É definir a infraestrutura que viabilizará a realização de cada entrevista. Os aspectos mais importantes a considerar são (COZBY, 2003): (i) definição do local e horário de início, (ii) tempo de duração de cada entrevista, (iii) uso de equipamentos, e (iv) escolha do entrevistador.

\section{- Local e horário de início e tempo de duração}

O local e horário escolhidos deverão ser convenientes ao entrevistado. O ambiente deverá possibilitar a livre discussão do tema, propiciando um clima informal na relação entrevistadoentrevistador, a fim de que comentários espontâneos sejam trazidos à tona mais facilmente (MINAYO et al., 2002).

O tempo de duração de cada entrevista não deve exceder a uma hora e trinta minutos, sob risco de a entrevista tornar-se cansativa e enfadonha (GREENBAUN, 2000; ROESCH, 2005; SANTOS e FOGLIATTO, 2002). 


\section{- Equipamentos e materiais necessários}

O material necessário deve incluir papéis para anotações, canetas e o roteiro previamente estabelecido. Cartões de papel para fazer apontamentos podem ser utilizados. No começo de cada entrevista, anota-se no cartão o nome do entrevistado, a hora em que teve início e final a entrevista e numeram-se os cartões à medida que prosseguem as entrevistas (VIEIRA e ZOUAIN, 2006).

É recomendável utilizar áudio durante as sessões, a fim de registrar o maior número possível de informações que possam advir dos entrevistados. Uma gravação fornece quantidade e expressão mais acurada de informações; no entanto, somente deve ser utilizada quando o entrevistado permite o seu uso e há planejamento claro para transcrever ou escutar sistematicamente o conteúdo coletado (RICHARDSON, 2007; ROESCH, 2005; GREENBAUN, 2000).

\section{Fase 6 - Escolher o entrevistador}

A adequada realização de uma entrevista envolve, além da estratégia de aplicação das perguntas, as habilidades do entrevistador (GIL, 2010). A disposição do entrevistado para responder não é algo automático. O entrevistador deve constituir a fonte de motivação para o entrevistado. Qualquer pessoa se dispõe a responder 3, 4 questões. Além dessa quantidade, é preciso convencê-la a responder (ROESCH, 2005). O entrevistador tem o desafio de adequar o entrevistado em papel que exceda a posição de mero respondente para transformá-lo em informante (GREENBAUN, 2000).

Um bom entrevistador deve apresentar as seguintes características: $(i)$ experiência na condução de entrevistas, (ii) empatia, apuradas memória, dicção, audição e concentração, (iii) administração do tempo de cada entrevista, (iv) estabelecimento e manutenção do nível de interesse do entrevistado, ( $v$ ) boa escrita, (vi) conhecimento sobre o assunto abordado, (vii) habilidade para captar informações verbais e não verbais dos entrevistados, e (viii) poder de inserção para intervir e pedir esclarecimentos (AAKER et al., 2003; BRADLEY, 1997; CHURCHILL, 2001; COZBY, 2003; GIL, 2010; ROESCH, 2005; VIEIRA e ZOUAIN, 2006).

\subsection{Condução das Entrevistas}

Uma boa condução da entrevista encoraja o entrevistado a manifestar sentimentos, ansiedades e frustrações, sem se sentir pressionado pela situação (RICHARDSON, 2007). Sugere-se que a entrevista inicie com o entrevistador dando as boas vindas ao entrevistado e explicitando o propósito da entrevista. Deve-se utilizar aproximadamente três minutos expondo o tema de pesquisa. Com isso, pretende-se despertar interesse na entrevista, gerar confiança no entrevistador, tornar o entrevistado mais envolvido com a pesquisa e ciente do tipo de informação requerido 
(JOLLEY e MITCHEL, 2009; VIEIRA e ZOUAIN, 2006).

Algumas instruções que auxiliam na condução de uma entrevista:

(i) explicar o objetivo e a natureza da pesquisa, dizendo ao entrevistado o porquê de ele ter sido escolhido;

(ii) assegurar o anonimato do entrevistado e o sigilo das respostas;

(iii) dar liberdade ao entrevistado para intervir quando necessário, pedir esclarecimentos e criticar o tipo de pergunta;

(iv) deixar para o final da entrevista a abordagem de temas delicados, haja vista a suposta empatia surgida no decorrer da entrevista;

(v) criar com o entrevistado ambiente de identificação e cordialidade;

(vi) permitir ao entrevistado concluir seu relato e ajudar a completá-lo;

(vii) evitar atitudes autoritárias ou paternalistas;

(viii) não dar conselhos nem fazer considerações moralistas;

(ix) evitar qualquer discussão relacionada com as consequiências das respostas;

(x) não apressar o entrevistado, dar-lhe o tempo necessário para que conclua o seu relato;

(xi) manter-se interessado na situação do entrevistado, mesmo durante momentos de silêncio, quando possivelmente o entrevistado estiver refletindo a respeito da pergunta realizada;

(xii) acompanhar atentamente o desenrolar da entrevista e estudar se o entrevistado está realmente internalizando o processo ou emitindo opiniões superficiais.

Existem diversos sintomas que ajudam a detectar problemas no transcurso da entrevista, tais como repetições, discordâncias, alusões, evasivas, etc. $\mathrm{O}$ entrevistador deve avaliar o surgimento desses sintomas a fim de intervir e retomar aspectos já colocados pelo entrevistado (CERVO et al, 2007; DIEHL e TATIM, 2004; GIL, 2010; RICHARDSON, 2007; GREENBAUN, 2000).

\subsection{Tratamento dos dados coletados}

Relaciona-se à síntese das várias opiniões obtidas durante as entrevistas e a busca por afinidades entre elas. Pretende-se, com o levantamento de dados, transformá-los em informação e associá-los ao propósito da pesquisa (DIEHL e TATIM, 2004; PEREIRA, 2004). O tratamento dos dados coletados (Etapa 3) é composto por três fases (Figura 3). 
Figura 3 - Fases que compõem a etapa de tratamento dos dados coletados

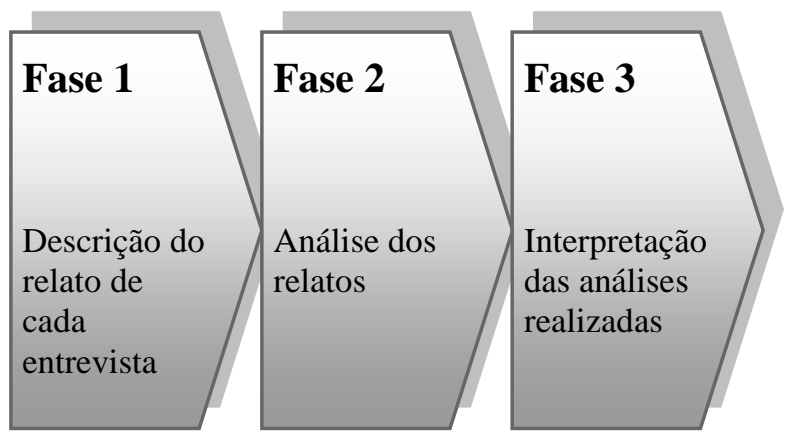

Fonte: realizado pelos autores.

\section{Fase 1 - Descrição do relato de cada entrevista}

Após a realização de cada entrevista faz-se a transcrição literal das anotações e/ou gravações, o que agiliza a tarefa seguinte, de análise de dados, e facilita a organização definitiva de cada relato. No caso de existirem registros sonoros, sugere-se ouvi-los em duas ocasiões. A primeira audição deve ser realizada sem interrupção, do início ao final da entrevista, para proporcionar uma visão geral e contextualização sobre a entrevista. Na segunda, deve-se procurar responder cada questão individualmente com o apoio dos relatos escritos (BRADLEY, 1997; RICHARDSON, 2007). Após a descrição, os dados devem ser organizados em formato que permitam classificá-los e categorizá-los. Os relatos devem ser organizados de forma coerente, incluindo, ocasionalmente, alguns comentários do entrevistador (SAURIN e RIBEIRO, 2000).

\section{Fase 2 - Análise dos relatos}

A análise tem por objetivo estabelecer relações entre o propósito da entrevista e o material descrito. Uma seqüência de procedimentos para conduzir a análise de dados pode ser assim estabelecida: (i) reconhecer e delimitar o propósito de estudo nos dados descritos, (ii) determinar uma estratégia eficiente de medida das respostas coletadas, por meio da análise de padrões detectados e de possíveis comparações, a fim de identificar a predominância de ideias, e (iii) efetivar a análise das medidas apuradas, ponderando propósito da pesquisa e potencial das medidas evidenciadas, no sentido de estabelecer relações de interpretação (GREENBAUN, 2000; PEREIRA, 2004; RICHARDSON, 2007). 


\section{Fase 3 - Interpretação das análises realizadas}

A interpretação conecta os dados analisados ao propósito estabelecido de antemão, possibilitando gerar explicação lógica e objetiva que esclareça o problema de pesquisa. A interpretação é a reflexão com avaliação crítica acerca de um assunto. (FLICK, 2008; PEREIRA, 2004).

O tratamento dos dados é concluído com a entrega e apresentação de um relatório final que resume os resultados obtidos. O relatório deve ser uma ferramenta de decisão. Para tanto, não é suficiente que se transcreva somente o que foi dito pelos entrevistados. Deve-se contextualizar as citações pertinentes ao propósito da entrevista e mencionar as implicações mais evidentes que surgiram dessas citações (RICHARDSON, 2007).

\section{Estudo de Caso}

A aplicação do método sugerido na seção 2 está exemplificada por um estudo de caso, a seguir detalhado. Nome da empresa e período de realização são omitidos a pedido.

\subsection{A empresa}

Trata-se de uma empresa pública prestadora de serviços em logística. Essa empresa tem atuação em âmbito nacional, com sede em Brasília/DF (Administração Central - AC), e representação em todos os estados da federação (Diretorias Regionais - DR). Na DR/RS (Rio Grande do Sul), a empresa tem cerca de 7.300 empregados lotados em áreas de atuação administrativa (30\%) e operacional (70\%). A área administrativa (suporte à área operacional) está centralizada em Porto Alegre. A área operacional (atividade fim) atua em quase todos os municípios do Rio Grande do Sul, em aproximadamente 500 unidades de atendimento à população.

\subsection{Medição do Desempenho Operacional}

As metas de desempenho da área operacional da DR/RS são definidas pela $\mathrm{AC}$, referenciadas em padrões de qualidade que atendam as necessidades dos clientes e mantenham a competitividade da empresa diante dos concorrentes.

Essas metas de desempenho operacional são desmembradas em quatro indicadores de avaliação e compiladas em um Relatório Mensal de Qualidade Operacional (RQO). O RQO traduz 
o desempenho de cada DR por meio de pontuação atribuída em uma escala (entre 0 e 11.000 pontos) que permite ranquear as DRs entre si e avaliar a sua qualidade individual. 10.000 pontos é o limite inferior para uma DR atender aos padrões de qualidade definidos pela AC.

\subsection{A situação "problema"}

No decorrer de três anos seguidos (Ano 1, Ano 2 e Ano 3), a DR/RS obteve resultados satisfatórios, com pontuação nunca inferior a 10.000 pontos.

A situação "problema" caracterizou-se a partir dos resultados insatisfatórios obtidos em Novembro do Ano 3. Naquele mês, a DR/RS obteve pontuação de 9.800 pontos. Nos meses seguintes, o decréscimo acentuou-se, a ponto de, entre Janeiro do Ano 4 e Maio do Ano 5, a DR/RS obter pontuação nunca superior a 9.300 pontos e classificada na última posição entre as DRs.

Em princípio, levantou-se a hipótese de que as causas do baixo desempenho eram consequência das mudanças dos gestores operacionais por questões "políticas" ocorridas no início do Ano 4 (mudança de governo). Porém, em uma primeira interpretação dos fatos, percebeu-se a falsidade da hipótese, haja vista que o baixo desempenho teve início ainda na gestão do governo anterior.

O Quadro 1 apresenta a relação entre período, desempenho e hipóteses iniciais para o baixo desempenho no decorrer do tempo na DR/RS. 
Quadro 1-Relação período x desempenho x responsabilidade x hipóteses iniciais

\begin{tabular}{|c|c|c|c|}
\hline \multicolumn{2}{|c|}{$\begin{array}{l}\text { Período } \\
\text { Analisado }\end{array}$} & Desempenho da DR/RS & Responsabilidade/Hipóteses iniciais \\
\hline \multicolumn{2}{|l|}{ Ano 1} & \multirow{12}{*}{$\begin{array}{l}\text { Mantém-se entre as } 13 \text { primeiras DRs } \\
\text { com pontuação total nunca inferior a } \\
10.000 \text { pontos. }\end{array}$} & \multirow{14}{*}{$\begin{array}{l}\text { Período sob responsabilidade da } \\
\text { Gestão Anterior }\end{array}$} \\
\hline \multicolumn{2}{|l|}{ Ano 2} & & \\
\hline \multirow{12}{*}{ Ano 3} & Jan & & \\
\hline & Fev & & \\
\hline & Mar & & \\
\hline & Abr & & \\
\hline & Mai & & \\
\hline & Jun & & \\
\hline & Jul & & \\
\hline & Ago & & \\
\hline & Set & & \\
\hline & Out & & \\
\hline & Nov & $\begin{array}{l}\text { Obtém } 9.800 \text { pontos e ocupa o } 17^{\circ} \\
\text { lugar entre as DRs. }\end{array}$ & \\
\hline & Dez & & \\
\hline \multirow{12}{*}{ Ano 4} & Jan & \multirow{17}{*}{$\begin{array}{l}\text { Pontuação nunca superior a } 9.300 \\
\text { pontos e última classificada entre as } \\
\text { DRs. }\end{array}$} & \multirow{17}{*}{$\begin{array}{l}\text { - As causas do baixo desempenho } \\
\text { estariam associadas à mudança dos } \\
\text { gestores da empresa por motivos } \\
\text { "políticos", a partir do Ano } 4 \text {. } \\
\text { - Percebe-se a falsidade na hipótese, haja } \\
\text { vista que o baixo desempenho começa a } \\
\text { ocorrer ainda durante a gestão anterior. }\end{array}$} \\
\hline & Fev & & \\
\hline & Mar & & \\
\hline & Abr & & \\
\hline & Mai & & \\
\hline & Jun & & \\
\hline & Jul & & \\
\hline & Ago & & \\
\hline & Set & & \\
\hline & Out & & \\
\hline & Nov & & \\
\hline & Dez & & \\
\hline \multirow{5}{*}{ Ano 5} & Jan & & \\
\hline & Fev & & \\
\hline & Mar & & \\
\hline & Abr & & \\
\hline & Mai & & \\
\hline
\end{tabular}

Fonte: realizado pelos autores.

Com o objetivo de levantar as possíveis causas para o baixo desempenho no período mencionado, buscou-se ouvir alguns funcionários da DR/RS, por meio da utilização de entrevistas individuais em profundidade, aplicando-se o método proposto na seção 2 .

\subsection{Etapa 1 - Planejamento da entrevista}

O planejamento segue as seis fases do método proposto (Figura 2) e detalhadas a seguir.

\section{Fase 1 - Definir o propósito da entrevista}

O propósito das entrevistas foi estabelecido como: levantar as possíveis causas que geraram os maus resultados operacionais por 19 meses, entre novembro do Ano 3 e maio do Ano 5, a partir da percepção de alguns empregados da DR/RS. Como subsídio à definição do propósito de 
pesquisa, utilizaram-se relatórios de desempenho referentes aos últimos quatro anos (entre Junho do Ano 1 e maio do Ano 5). A análise dos relatórios permitiu identificar tópicos de interesse a serem apresentados aos entrevistados em forma de perguntas.

\section{Fase 2 - Identificar e convidar entrevistados}

A identificação dos entrevistados ocorreu por consulta ao cadastro de empregados da empresa, a fim de levantar aqueles que trabalharam na área operacional da DR/RS entre janeiro do Ano 3 e maio do Ano 5. Para incluir um empregado no grupo de entrevistados, associaram-se três outras variáveis: $(i)$ tempo de serviço na empresa, (ii) enquadramento do cargo ocupado no plano de carreiras da empresa, e (iii) status da posição de comando dentro da empresa. A escolha dessas variáveis buscou representação diversificada de empregados vinculados à área operacional da DR/RS, a fim de permitir comparações e análises das respostas a serem coletadas.

Para a variável "tempo de serviço na empresa", considerou-se o número de anos em que cada funcionário trabalha na empresa. Quatro estratos de detalhamento foram elaborados, considerando as faixas: (i) até 2 anos de trabalho, (ii) entre 2 e 5 anos, (iii) entre 5 e 10 anos e (iv) mais de 10 anos.

Para "enquadramento do cargo ocupado no plano de carreiras da empresa", utilizou-se a nomenclatura oficial que distingue os cargos em nível básico (B), médio (M) e superior (S), de acordo com a escolaridade assumida pelo empregado. Os cargos de nível médio e superior são aqueles que podem ocupar posição de comando.

A variável "status da posição de comando dentro da empresa" foi estratificada em quatro níveis: (1) estar ocupando posição de comando entre novembro do Ano 3 e maio do Ano 5, (2) assumir posição de comando após maio do Ano 5, (3) não estar ocupando posição de comando antes, durante e após maio do Ano 5 - (3), e (4) estar ocupando posição de comando antes, durante e após maio do Ano 5 (4).

Após o levantamento e análise das quatro variáveis definidas, optou-se por realizar entrevistas com oito participantes, escolhidos em amostragem por julgamento, de acordo com o perfil constante na Tabela 1. A amostragem por julgamento buscou captar entrevistados que pudessem contribuir para o propósito da pesquisa. Os requisitos para validação dos participantes consideraram conhecimento a respeito das rotinas e acompanhamento sistemático do desempenho operacional da DR/RS. 
Tabela 1:Perfil dos entrevistados

\begin{tabular}{c|c|c|c}
\hline Entrevistado & $\begin{array}{c}\text { Tempo de serviço } \\
\text { na empresa } \\
\text { (em anos) }\end{array}$ & $\begin{array}{c}\text { Enquadramento do } \\
\text { cargo ocupado na } \\
\text { hierarquia da empresa }\end{array}$ & $\begin{array}{c}\text { Status da posição de } \\
\text { comando dentro da } \\
\text { empresa }\end{array}$ \\
\hline $\mathrm{X}$ & 20 & $\mathrm{~S}$ & 1 \\
\hline $\mathrm{Y}$ & 6 & $\mathrm{M}$ & 1 \\
\hline $\mathrm{Z}$ & 4 & $\mathrm{M}$ & 2 \\
\hline $\mathrm{K}$ & 15 & $\mathrm{M}$ & 2 \\
\hline $\mathrm{L}$ & 4 & $\mathrm{~S}$ & 3 \\
\hline $\mathrm{M}$ & 11 & $\mathrm{~S}$ & 3 \\
\hline $\mathrm{N}$ & 8 & $\mathrm{~S}$ & 4 \\
\hline $\mathrm{O}$ & 2 & $\mathrm{~B}$ & 4 \\
\hline
\end{tabular}

Fonte: realizado pelos autores.

\section{Fase 3 - Estabelecer uma oportunidade}

As entrevistas foram agendadas com dez dias de antecedência em datas que os entrevistados pudessem participar, sem que o trabalho rotineiro fosse prejudicado ou a entrevista não pudesse seguir um fluxo normal de realização. Os contatos iniciais foram mantidos pessoalmente. Nesses contatos, o possível entrevistado recebeu informações relativas ao propósito da entrevista, à necessidade da obtenção das informações, ao caráter do trabalho científico que estava sendo realizado e ao convite final para participação. Dos oito entrevistados inicialmente previstos, seis concordaram ao final da explanação e dois optaram por não participar. Dessa forma, recorreu-se novamente ao cadastro de empregados em busca de outros dois possíveis participantes. A escolha dos substitutos foi realizada de forma similar à anterior, quando se obtiveram as respectivas concordâncias.

Um dia antes da realização da entrevista, manteve-se contato com cada entrevistado, a fim de lembrar-lhe sobre o evento. Assim mesmo, no intuito de reforçar o lembrete, foi utilizado o recurso de agenda constante no software Microsoft Outlook para que, 30 minutos antes de cada entrevista, o participante fosse avisado a respeito do compromisso, já que os escolhidos dispunham de computador individual no ambiente de trabalho. Todas as entrevistas foram realizadas nos dias e horários previstos entre 04 e 26 de maio do Ano 5.

\section{Fase 4 - Elaborar questões e roteiro}

Para realizar as entrevistas um roteiro em três partes foi elaborado.

A primeira parte referiu-se a lembretes sobre a abertura da entrevista, agradecimentos pela participação, apresentação do entrevistador, reiteração sobre as razões de realização do trabalho e o caráter científico do mesmo.

$\mathrm{Na}$ segunda parte, apresentou-se ao entrevistado a relação de perguntas. A entrevista assumiu forma semiestruturada, ou seja, as perguntas poderiam ser desmembradas em outras 
perguntas de interesse caso se fizesse necessário. As perguntas iniciais tiveram enfoque bastante abrangente, com a intenção de "quebrar o gelo" e iniciar a conversação. Tais perguntas visaram contextualizar o entrevistado no ambiente da empresa até se chegar às perguntas de interesse específico e vinculadas ao propósito definido na Fase 1 da Etapa 1. As perguntas apresentadas na parte inicial das entrevistas foram as seguintes:

1) Qual o seu tempo de trabalho na Empresa?

2) Em quais órgãos da empresa você trabalhou nesse período?

3) Nos últimos quatro anos (entre Junho do Ano 1 e maio do Ano 5) em quais processos da área operacional você atuou?

4) Em sua opinião, o que é importante para uma empresa obter resultados operacionais satisfatórios?

5) Você tem acompanhado os resultados operacionais da DR/RS no período Ano 3 /

\section{Ano 4 / Ano 5?}

6) Você tem ideia a respeito das causas que podem ter gerado baixos índices operacionais para a DR/RS no Ano 4 e 5 ?

7) Em sua opinião, as causas do baixo desempenho estão relacionadas a situações regionais ou nacionais dentro da Empresa?

8) Por que tais índices só ocorreram no âmbito da DR/RS?

9) Quais os principais motivos que conduziram a DR/RS a resultados insatisfatórios no

\section{Ano 4?}

10) Você tem alguma outra consideração a apresentar sobre o desempenho operacional da DR/RS?

A terceira parte do roteiro foi destinada: $(i)$ aos agradecimentos finais pela participação e explanação sobre os tópicos de interesse, e (ii) a explicações relativas ao tratamento dos dados coletados durante a entrevista.

\section{Fase 5 - Detalhar aspectos logísticos}

Com relação aos aspectos logísticos de realização das entrevistas definiu-se o seguinte:

$\left.\mathbf{1}^{\mathbf{o}}\right)$ Local e horário de início e tempo de duração

As entrevistas foram realizadas em ambiente neutro e tranqüilo, que permitisse realizar cada entrevista sem interrupções. Utilizou-se uma sala de reuniões preparada para a realização dos encontros.

Cada entrevista foi programada para ter início no começo da jornada de trabalho de cada empregado, em concordância entre entrevistador e entrevistado, a fim de facilitar a conversação. As entrevistas duraram em média 56 minutos. A entrevista com maior tempo de duração realizou-se em 
1 hora e 22 minutos. A entrevista com menor tempo de duração efetivou-se em 43 minutos.

$\mathbf{2}^{\mathbf{0}}$ ) Equipamentos e materiais necessários

Em cada entrevista foram utilizados: $(i)$ o roteiro e as perguntas previamente definidos, $(i i)$ caneta e folhas de papel para anotações de pontos chaves contidos nas respostas de cada entrevistado, e (iii) gravador para registrar as falas de cada entrevistado, já que houve concordância unânime para que esse procedimento fosse realizado.

\section{Fase 6 - Escolher o entrevistador}

O entrevistador foi escolhido por apresentar quatro características consideradas relevantes para a execução das entrevistas: $(i)$ já ter conduzido outras entrevistas com funcionários da empresa foco, (ii) ter contato frequiente com os entrevistados, o que amenizou a relação inicial e permitiu acesso tranqüilo para que se realizasse cada entrevista, (iii) ter conhecimento do processo operacional em análise, e (iv) ter recebido orientação teórica a respeito dos fundamentos para realizar pesquisas qualitativas.

\subsection{Etapa 2 - Condução das entrevistas}

A condução das entrevistas ocorreu de forma amistosa, possibilitando aos entrevistados sentirem-se à vontade para realizar quaisquer intervenções no desenrolar dos encontros.

A condução seguiu o roteiro previsto. Em razão dos vários questionamentos apresentados pelos entrevistados, o número de perguntas realizado excedeu àquelas dez previamente definidas.

Ao final das entrevistas, cinco dos oito entrevistados foram categóricos com relação à importância de realização da entrevista. Argumentaram que o contato serviu de motivo para reflexão sobre a sistemática de avaliação de desempenho operacional da DR/RS, sua retomada e discussão junto aos demais funcionários da empresa.

\subsection{Etapa 3 - Tratamento dos dados coletados}

O tratamento dos dados ocorreu por aplicação das três fases constantes na Figura 3, a seguir detalhadas:

\section{Fase 1 - Descrição dos relatos de cada entrevista}

A descrição dos relatos foi obtida das anotações e gravações realizadas, materializando-se por meio da transcrição literal das principais ideias apontadas e relacionadas ao propósito de realização da pesquisa, o de captar a percepção dos entrevistados sobre as possíveis causas do baixo desempenho operacional da DR/RS nos Anos 3, 4 e 5. A descrição dos relatos permitiu delinear 
uma estrutura de informação para balizar a fase subseqüente (análise dos dados) e que correlacionasse as ideias surgidas ao propósito da pesquisa.

\section{Fase 2 - Análise dos dados}

A análise de dados seguiu os três procedimentos mencionados em 2.3, Fase 2:

10) Reconhecimento e delimitação das ideias relacionadas diretamente ao propósito de pesquisa definido na Fase 1. As principais ideias levantadas por entrevistado estão descritas no Anexo I.

$\mathbf{2}^{\mathbf{0}}$ ) Definição de uma estratégia de medida das ideias apresentadas, selecionando palavras frequentes e mensurando o número de vezes em que as mesmas foram mencionadas pelos entrevistados (e escolhendo aquelas com maior frequência de citação). Constatou-se a menção das palavras "treinamento" e "desqualificação" em 55 e 35 vezes, respectivamente. A partir das palavras identificadas, ideias associadas foram relacionadas, quais sejam:

\section{$\underline{\text { Treinamento }}$}

- Falta de treinamento em todos os níveis hierárquicos da empresa;

- Substituição do treinamento em sala de aula por treinamentos rápidos em local de trabalho;

- Falta de normas claras a respeito da execução dos processos;

- Falta de investimentos em treinamento;

- Não realização de treinamento para os empregados adaptarem-se ao equipamento de triagem automático de objetos;

- Não integração de homem/máquina, a partir do Ano 3, com a mecanização dos processos de triagem de objetos na DR/RS;

- Não realização de treinamento explicativo sobre o desempenho operacional exigido;

- Alienação do trabalho (as pessoas não sabem o porquê de fazerem as suas tarefas); e

- Despadronização (falta de padrão como referência) na realização dos processos.

\section{$\underline{\text { Desqualificacãa }}$}

- Falta de habilitação das pessoas para assumir posições de comando;

- Não compreensão do significado de indicadores por boa parte dos empregados e chefias;

- Despreparo dos empregados para aprender novos conhecimentos, novas técnicas (estagnação da empresa); 
- Desqualificação dos gestores, que desconhecem as formas de avaliação de desempenho dos funcionários;

- Não compreensão de índices e fórmulas de cálculo por boa parte dos gestores;

- Desvalorização dos empregados e maior valorização ao equipamento de mecanização operacional; e

- Excesso de empirismo na tomada de decisão.

$3^{\text {o }) ~ C o n j u n c ̧ a ̃ o ~ d a s ~ i d e i a s ~ " t r e i n a m e n t o " ~ e ~ " d e s q u a l i f i c a c ̧ a ̃ o ", ~ a p r e s e n t a n d o ~ i n t e r p r e t a c ̧ o ̃ e s ~ e ~}$ inferências conectadas às possíveis causas do baixo rendimento operacional. Apesar de os termos "treinamento" e "desqualificação" apresentarem relação de causa-consequiência, já que a falta de treinamento estimula a desqualificação profissional, o enfoque dado pelos entrevistados não vinculou diretamente as duas terminologias. Constatou-se que as palavras "treinamento" e “desqualificação” foram apresentadas pelos entrevistados de forma independente.

Com relação ao tópico treinamento, as nove ideias apresentadas puderam ser subdividas nos enfoques "falta" e "substituição" de treinamento. No enfoque "falta de treinamento" os entrevistados referiram-se à insuficiência de horas de treinamento que são realizadas no âmbito da DR/RS e que podem ter contribuído para o baixo desempenho operacional. Porém, em consulta à área de treinamento, constatou-se que as metas de hora de treinamento por empregado vinham sendo superadas. A DR/RS estabelecia uma meta de 40h/funcionário/semestre e o índice obtido havia sido de $44 \mathrm{~h}$.

Dessa forma, a argumentação dos entrevistados é improcedente na medida em que a área de treinamento cumpriu seus objetivos. Cabe, por isso, o questionamento quanto à necessidade de a DR/RS rever se a meta de carga horária é suficiente para atender à demanda operacional ou se essa demanda deve ser direcionada para assuntos diferentes daqueles até então tratados. Presume-se não ter havido sintonia entre as demandas da área operacional e práticas de treinamento. Outra evidência dessa falta de harmonia referiu-se às várias menções relativas à despadronização na realização de processos como causa do baixo rendimento. Ou seja, é possível que os empregados lotados na área operacional ressintam-se da falta de treinamento específico e que essa falta ocasionou erros na execução de procedimentos.

Por fim, há investimento em treinamento (valor decrescente nos últimos 5 anos), porém se constatou a inexistência de ações que vinculem treinamento às metas e resultados operacionais.

Já no enfoque "substituição de treinamento", há pensamento majoritário de que a prática de realizar Treinamento em Local de Trabalho (TLT), em substituição ao treinamento em sala de aula, é inadequada. A DR/RS, como forma de acelerar o acesso ao conhecimento, optou por designar os 
próprios empregados da área operacional para ministrar treinamento no local do trabalho, independente do grau de conhecimento acerca de determinado tópico.

Constatou-se nos entrevistados o descrédito com relação a essa forma de treinamento. $\mathrm{Na}$ opinião dos mesmos, o TLT não agrega o conhecimento necessário, dado o despreparo dos supostos instrutores. Esse argumento encontra fundamento na teoria existente que entrelaça motivação e treinamento. De acordo com especialistas na área de Recursos Humanos, um dos pilares de realização do treinamento é a expectativa e a motivação criada nos treinandos com relação à captação de novos conhecimentos. O treinamento torna-se uma demonstração de importância e valorização do empregado pela instituição em que trabalha (MACEDO et al., 2011).

O TLT pode não ser a causa do baixo desempenho operacional; todavia, há indicativos de que tal forma de treinamento não é bem aceita pelos empregados. Caberia à empresa estabelecer instrumento de avaliação da efetividade do TLT. Caso fique comprovada a sua eficácia, os resultados devem ser apresentados aos empregados, a fim de desmistificar os valores negativos já consagrados.

Contudo, a argumentação do TLT como causa do baixo desempenho parece infundada, haja vista que a política de treinamento da empresa é elaborada igualmente por todo o Brasil e o desempenho operacional no país foi melhorado no período em questão. Nesse sentido, a DR/RS deveria contactar com outras DRs que não tiveram seus índices operacionais rebaixados, a fim de verificar qual a estratégia adotada para que o resultado tivesse sido satisfatório.

Com relação ao tópico desqualificacãa, as sete ideias apresentadas foram agrupadas em outras duas: "desqualificação para executar uma atividade" e "desqualificação para exercer uma posição de comando".

No que se refere à "desqualificação para executar uma atividade", predominou o pensamento relacionado à falta de preparo dos empregados para lidar com as novas tecnologias adquiridas pela DR/RS. Quatro entrevistados alegaram dificuldades para traduzir as informações oriundas de equipamentos recém-adquiridos e diretamente vinculados ao desempenho operacional. Conseqüentemente, a obtenção dos respectivos rendimentos, análises imediatas e tomadas de decisão ficaram comprometidas.

Há evidências claras para corroborar essa hipótese, pois a empresa, por exemplo, adquiriu equipamentos sofisticados para triagem de objetos na área operacional, e, passados dois anos desde a aquisição, realizou treinamento para apenas cinco empregados com posição de comando. Não houve planejamento de multiplicação de conhecimento para os demais empregados. O efetivo dos empregados adquiriu conhecimento por tentativa e erro. $\mathrm{O}$ empirismo em questão ratifica a posição de risco adotada pela DR/RS. Uma decisão mais técnica poderia ter evitado perdas relacionadas a tempo, dinheiro e recursos humanos (HAGUE e JACKSON, 1997). 
No que se refere à "desqualificação para exercer posição de comando", no desenrolar das entrevistas ficou caracterizado o despreparo dos mesmos com relação às metas e formas de avaliação de desempenho. Apesar de todos os entrevistados dizerem-se conhecedores dos indicadores definidos pela DR/RS, apenas um deles sabia, por exemplo, que os equipamentos automatizados emitem relatórios de desempenho diário.

Sete entrevistados alegaram tomar conhecimento dos resultados de desempenho operacional apenas no décimo quinto dia do mês subseqüente ao da realização das atividades; ou seja, somente depois de encerrado o mês, quando do envio para a DR/RS do relatório (RQO) emitido pela AC. Sete entrevistados desconheciam a possibilidade a qualquer chefia ou empregado de acompanhar o resultado operacional dentro do próprio mês (on line ou no dia seguinte) e poder avaliar e corrigir qualquer falha operacional imediatamente detectada.

Além disso, no decorrer da entrevista, percebeu-se que nenhum dos entrevistados sabia como se calculavam os índices constantes no RQO. Houve referências de três entrevistados para fórmulas e cálculos "mirabolantes e incompreensíveis" que impedem o acompanhamento mais pormenorizado de resultados.

Os termos treinamento e desqualificação foram abordados em separado, porém carecem de vinculação. Percebe-se que o desconhecimento sobre as novas formas de trabalho e a análise imediata de resultados é bastante evidente e requer atuação maciça da área de treinamento para a sua erradicação. É fato notório que recentemente a DR/RS passou por um processo de automatização de seus processos e que o grupo de empregados não acompanhou a contento essa evolução.

Tal afirmativa condiz com o pensamento de que a interação homem-máquina não é imediata e requer preparação e conhecimento (CATTANI e HOLZMANN, 2011). Por isso, cabe à área de treinamento proporcionar essa interação e acelerar o processo de aprendizagem para que rendimentos admissíveis sejam obtidos. Porém, o fortalecimento do trinômio "capacitação $\mathrm{x}$ operação x produtividade" somente ocorrerá com apoio do alto escalão da DR/RS. Na percepção de quatro entrevistados, o corpo diretivo não parece plenamente engajado à automatização dos processos e à sua aplicação na área operacional. Para essas pessoas, falta comunicação entre a Direção Regional e a sua área operacional.

A partir dos depoimentos prestados pelos entrevistados, pode-se deduzir que o diferencial entre a DR/RS e as demais DRs pode ser o foco de atuação da área de treinamento como promovedora de qualificação. Parece não haver sincronização entre o que área de treinamento propõe e as necessidades de sua clientela, no caso a área operacional.

Outros motivos emergiram da pesquisa e podem ter contribuído para que os resultados tivessem sido insatisfatórios. É perceptível que todas as causas permeiam a questão da gestão 
operacional da DR/RS. Durante período de aproximadamente um ano, parece ter ocorrido um momento de inércia e incredulidade com relação aos baixos resultados, a ponto de poucas medidas corretivas terem sido tomadas e os resultados melhorados.

\section{Considerações Finais}

Este artigo propôs um método para compreender a ocorrência de situações de origem qualitativa, por meio da definição de etapas sincronizadas e associadas à aplicação de entrevistas em profundidade.

No desenvolvimento dessas etapas, aprofunda-se o conhecimento sobre determinado tópico e direciona-se a investigação para interpretar um fenômeno, utilizando-se de um critério que permita sistematizar a compreensão desse fenômeno.

Sob a forma de um estudo de caso, a prática do método identificou possíveis causas de baixo desempenho operacional, valendo-se de entrevistas em profundidade para levantar a percepção de 8 empregados de uma empresa prestadora de serviços logísticos.

O método mostrou-se muito pertinente, haja vista a qualidade das percepções alavancadas pelos entrevistados, as quais foram descritas, analisadas e interpretadas de forma sistemática e logicamente compreendidas. Ao final das entrevistas, dois tópicos ficaram evidenciados como mais citados pelos participantes: treinamento e qualificação. Apesar da similaridade entre tais assuntos, o método permitiu apontar as especificidades relacionadas a cada um deles, associando-as à realidade, às teorias existentes, assim como desfazendo mitos derivados da prática operacional de cada entrevistado. Mesmo que os tópicos não sejam determinantes para a melhoria do desempenho operacional, o relatório final emitido serve de referência para a empresa direcionar futuras políticas de atuação junto aos seus empregados.

\section{Abstract}

This paper proposes a method to understand the occurrence of situations that had been originated from qualitative nature. The method defines three macrosteps with procedures to plan, manage and treat collected data through in-depth interviews. Each step is broken down into sequential phases that support the formation of judgment about a topic of interest. This sequence describes respondents' talkings, analyzes and interprets them, trying to capture in collected talkings common points of perception which will serve as a reference for understanding certain situation and assist in decision making. To validate the method, a case study is applied in a state company (logistics operator), where, for about 19 months, the performance remained below expectations in a given region inside Brazil, without being possible to identify the real reasons that led this company to such a bad result. The case study allowed to interview eight employees previously chosen and raise possible causes of low operational performance in a systematic and objective look. As a result, the method is shown to be feasible and easily applied to be used in similar situations. This reinforces its application while a possibility of joining ideas that can demystify levels of guessing so commonly 
realized in administrative environments and that, often, predefine actions, processes and people, directing the decision-making to wrong ways and not connected to the root causes of problems.

Key-words: method, in-depth interviews, description, analysis and interpretation.

\section{Referências}

AAKER, D.A.; DAY, G.S.; KUMAR V., Marketing research, 8ª Ed., New York: John Wiley Sons, Inc., 2003.

AYLOTT, R.; MITCHELL, V.W., An exploratory study of grocery shopping stressors. International Journal of retail and Distribution Management, v.26, n. 9, p. 683-700, 1998. crossref

BRADLEY, L. M., Using theory to structure qualitative research: an investigation of gender and identity in performance appraisal. Academy of management proceedings, v. XIII, p. 386-390, Australia, 1997.

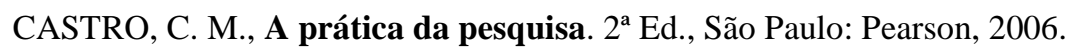

CATTANI, A. D.; HOLZMAN, L., Dicionário de Trabalho e Tecnologia. 2a Ed., Porto Alegre: Zouk, 2011.

CERVO, A. L.; BERVIAN, P. A.; SILVA, R., Metodologia científica. 6ª Ed., São Paulo: Pearson, 2007.

CHURCHILL, G. A., Basic marketing research. $4^{\text {a }}$ Ed., New York: The Dryden Press, 2001.

CHURCHILL, G.A.J.; PETER J.P., Marketing: criando valor para o cliente. $2^{\mathrm{a}}$ Ed., São Paulo: Saraiva, 2010.

COZBY, P. C., Métodos de pesquisa em ciências do comportamento. 1ª Ed., São Paulo: Atlas, 2003.

CRESWELL, J. W. Projeto de pesquisa: métodos qualitativo, quantitativo e misto. $3^{\text {a }}$ Ed., Porto Alegre: Artmed, 2010.

DIEHL, A. A.; TATIM, D. C., Pesquisa em ciências sociais aplicadas. 1ª Ed.,São Paulo: Pearson, 2004.

FLICK, U., Desenho da pesquisa qualitativa. $1^{\text {a }}$ Ed.,Porto Alegre: Bookman, 2008.

GIL, A. C. Como elaborar projetos de pesquisa. 5a Ed., São Paulo: Atlas, 2010.

GREENBAUN, T.L., Moderating focus groups: a practical guide for group facilitation. $1^{\text {a }}$ Ed., London: Sage Publications, 2000. crossref

GREENHALGH, T.; TAYLOR, R., Papers that go beyond numbers (qualitative research). British Medical Journal, v.315, n.7110, p.740-743, Londres, setembro, 1997.

HAGUE P.; JACKSON P., Faça sua própria pesquisa de mercado, 1ª Ed., São Paulo: Nobel, 1997.

JOLLEY, J.M.; MITCHELL, M.L., Research Design Explained, 7ª Ed., Belmont: Wadsworth Cengage Int., 2009.

MACEDO, I.I.D.; RODRIGUES, D.F.; JOHAN, M.E.P.; CUNHA, N.M.M.D., Aspectos comportamentais da gestão de pessoas, $9^{a}$ Ed., São Paulo: FGV, 2011.

MATTAR, F.N. Pesquisa de marketing. 6 6 Ed., São Paulo: Atlas, 2005.

MINAYO, M.C.S., DESLANDES, S.F., NETO, O.C.; GOMES, R., Pesquisa social: teoria, método e criatividade, $27^{\mathrm{a}}$ Ed., Petrópolis: Vozes, 2002.

PEREIRA, J.C.R., Análise de dados qualitativos: estratégias metodológicas para as ciências da saúde, humanas e sociais. $3^{\text {a }}$ Ed., São Paulo: Edusp, 2004.

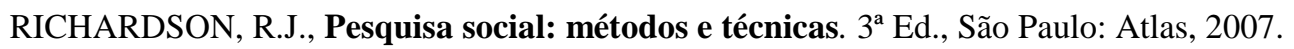

ROESCH, S.M.A., Projetos de estágio e de Pesquisa em Administração. $3^{\text {a }}$ Ed., São Paulo: Atlas, 2005. 
SANTOS, G. T. ; FOGLIATTO, F. S. . Grupos Focalizados: uma proposta de roteiro para identificação de atributos de preferência. In: XXII ENEGEP, 2002, Curitiba. Grupos focalizados: uma proposta de roteiro para identificação de atributos de preferência, 2002.

SAURIN, T.A.; RIBEIRO, J.L.D. Segurança no trabalho em um canteiro de obras: percepções dos operários e da gerência. Revista Produção, v. 10, n.1., p.5-17, Rio de Janeiro, 2000.

VIEIRA, M.M. F.; ZOUAIN D.M., Pesquisa qualitativa em administração. 2a Ed., Rio de Janeiro: FGV, 2006.

\section{Dados dos autores:}

Nome completo: Gilberto Tavares dos Santos

Filiação institucional: Universidade Federal do Rio Grande do Sul, Porto Alegre (RS)

Departamento: Escola de Administração

Função ou cargo ocupado: Professor do Magistério Superior

Endereço completo para correspondência: Rua Washington Luiz, 855 - Centro Histórico, Porto

Alegre - RS, CEP 90010-460

Telefones para contato: +55 (51) 3308-3536

E-mail: gilberto.tavares@ufrgs.br

Nome completo: Rogério Royer

Filiação institucional: Universidade Federal de Pelotas, Pelotas (RS)

Departamento: Centro de Engenharias - Engenharia de Produção

Função ou cargo ocupado: Professor do Magistério Superior

Endereço completo para correspondência: Centro de Engenharias-Prédio da Antiga Cotada, Rua

Benjamin Constant, 989 - Porto Pelotas - RS, Brasil - CEP 96010-020

Telefones para contato: +55 (53) 3284-1700

E-mail:rogroyer@ufrgs.br

Nome completo: Vicente Henrique de Oliveira Filho

Filiação institucional: Pontifícia Universidade Católica, São Paulo (SP)

Departamento: Escola de Educação - Matemática

Função ou cargo ocupado: Doutorando

Endereço completo para correspondência: Rua Marquês de Paranaguá, 111 - Prédio 1 - $2^{\circ}$ andar -

Consolação - 01303-050 - São Paulo - SP - Brasil

Telefones para contato: +55 (11) 3124-7200

E-mail:enriqueoliver2005@yahoo.com.br 
Nome completo: Ariane Ferreira Porto Rosa

Filiação institucional: Universidade Federal de Pelotas, Pelotas (RS)

Departamento: Centro de Engenharias - Engenharia de Produção

Função ou cargo ocupado: Professor do Magistério Superior

Endereço completo para correspondência: Centro de Engenharias-Prédio da Antiga Cotada, Rua

Benjamin Constant, 989 - Porto Pelotas - RS, Brasil - CEP 96010-020

Telefones para contato: +55 (53) 3284-1700

E-mail: afprosa61@gmail.com

Submetido em:11-11-2016

Aceito em: $31 / 12 / 2016$ 